Lesser Sunda

P-ISSN: 2775-0078

Januari 2021

E-ISSN: 2775-0086

Vol. 1(3):15-23

\title{
Valuasi Ekonomi Sumberdaya Terumbu Karang di Kawasan Konservasi Gita Nada - Sekotong
}

\author{
Sitti Hilyana ${ }^{1 *}$, Sadikin Amir ${ }^{1}$, Nurliah Buhari ${ }^{1}$, Saptono Waspodo ${ }^{1}$, Soraya Gigentika ${ }^{1}$ \\ ${ }^{1}$ Program Studi Ilmu Kelautan, Jurusan Perikanan dan Ilmu Kelautan, \\ Fakultas Pertanian, Universitas Mataram \\ *sittihilyana@unram.ac,id
}

Naskah diterima : 5 Desember 2020, Disetujui : 13 Januari 2021

\begin{abstract}
Economic valuation is an important instrument in making policies for managing coral reef resources effectively and efficiently and is able to distribute the value of benefits and costs in developing conservation areas. This study aims to determine the economic valuation of coral reef resources in TWP Gita Nada Sekotong Lombok Barat Regency. The research used the survey method with a sample size of 45 respondents determined by purposive random sampling based on the status of the respondent. Data analysis uses the Total Economic Value (TEV) approach by aggregating the value of direct benefits, indirect benefit values, value of selected benefits, value of existence benefits, and value of inheritance benefits. The results showed that the TEV of coral reef in TWP Gita Nada was Rp. 147,976,915,107.98/year or IDR 54,778,806.30/ha/year. The value of indirect benefits contributed IDR 113,523,601,904.00 per year (76.7\% of the total economic value of coral reefs), while the direct benefit contributes $R p$. $34,453,313,203.98$ per year (23.3\% of the total economic value of coral reefs).
\end{abstract}

Keywords : Economic valuation, conservation areas, coral reefs

\section{PENDAHULUAN}

Kawasan Perairan Gili Tangko, Gili Nanggu dan Sudak (Gita Nada) Sekotong Lombok Barat ditetapkan sebagai Taman Wisata Perairan (TWP) berdasarkan SK Menteri Kelautan dan Perikanan Nomor 93 Tahun 2018. TWP Gita Nada memiliki nilai keanekaragaman hayati yang tinggi serta memiliki kekhasan dan keaslian yang alami sehingga ditetapkan sebagai kawasan konservasi dengan fungsi perlindungan, pelestarian dan pemanfaatan. TWP Gita Nada memiliki ekosistem terumbu karang seluas 2.701,6 Ha (DKP Lobar, 2013).
Ekosistem terumbu karang mempunyai peranan yang penting secara ekologi karena merupakan habitat berbagai jenis biota (McCook et al., 2009). Ekosistem terumbu karang menjadi daerah pemijahan, pengasuhan dan daerah mencari makan berbagai jenis ikan. Olehnya itu, ekosistem terumbu karang di Gita Nada dimanfaatkan sebagai daerah penangkapan ikan (Yulianto et al., 2019) dan daerah wisata (Witomo et al., 2020).

Kebutuhan untuk memenuhi kepentingan keberlanjutan ekologis dan kepentingan ekonomi, pemahaman tentang 
konsep valuasi ekonomi sangat penting sebagai dasar pijak pengelolaan sumber daya agar dapat dimanfaatkan secara efektif dan efesien. Valuasi ekonomi merupakan instrument penting yang dibutuhkan dalam kebijakan ekonomi sumber daya karena dapat menggambarkan adanya net incremental benefit dari strategi pengelolaan kawasan konservasi. Nilai ekologis yang dikonversi ke dalam nilai ekonomi dapat dijadikan acuan dalam menetapkan ganti rugi apabila terjadi kerusakan sumber daya. Tujuan penelitian diarahkan untuk mengetahui total nilai ekonomi ekosistem terumbu karang pada TWP Gita Nada.

\section{METODE PENELITIAN}

Penelitian dilakukan di TWP Gita Nada Kecamatan Sekotong, Kabupaten Lombok Barat, Provinsi NTB selama 16 minggu pada bulan Juli hingga Oktober 2019. Data tentang luasan dan kondisi terumbu karang yang digunakan dalam analisis diperoleh dari Dinas Kelautan dan Perikanan (DKP) Kabupaten Lombok Barat (DKP Lobar, 2013). Pengumpulan data primer dilakukan dengan teknik wawancara secara terstruktur menggunakan kuesioner, Focus
Group Discussion (FGD), serta konsultasi public. Wawancara mendalam dilakukan dengan informan kunci. FGD dilakukan dengan melibatkan pemanfaat terumbu karang di TWP Gita Nada dengan menelayan, wisatawan, serta akademisi. Konsultasi Publik dilakukan untuk mengkonfirmasi hasil penilaian dengan pemangku kepentingan terkait.

Analisis nilai manfaat terumbu karang di TWP Gita Nada mengmenggunakan pendekatan Total Economic Value (Barton, 1994) dengan tipologi penilaian seperti yang ditunjukan pada Gambar 1 dan dijelaskan detailnya pada Tabel 1.

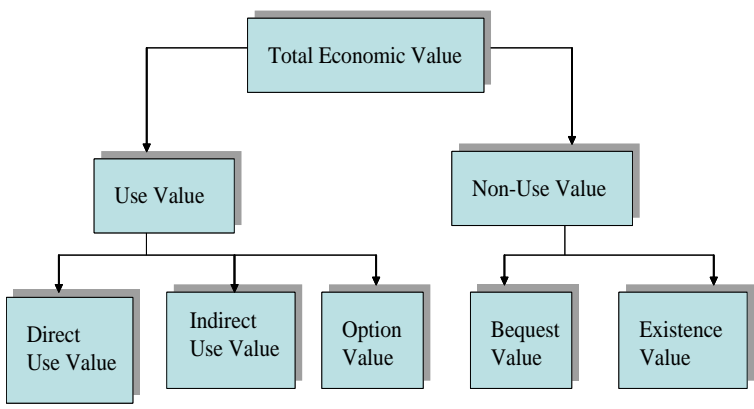

Gambar 1 Tipologi Penilaian Total Economic Value (Barton, 1994)

Tabel 1 Penjelasan Mengenai Tipologi Nilai untuk Penilaian Total Economic Value

\begin{tabular}{lll}
\hline No & \multicolumn{1}{c}{ Tipologi Nilai } & \multicolumn{1}{c}{ Definisi } \\
\hline I. & Use value & \\
& 1. Direct use value & $\begin{array}{l}\text { Nilai ekonomi yang diperoleh dari pemanfaatan langsung dari } \\
\text { sebuah ekosistem/sumberdaya }\end{array}$ \\
& & $\begin{array}{l}\text { Nilai ekonomi yang diperoleh dari pemanfaatan tidak langsung dari } \\
\text { s. Inderect use value ekosistem/sumberdaya }\end{array}$ \\
& & $\begin{array}{l}\text { Nilai ekonomi yang diperoleh dari potensi pemanfaatan langsung } \\
\text { maupun tidak langsung dari sebuah ekosistem/sumberdaya di masa } \\
\text { mendatang }\end{array}$
\end{tabular}

II. Non use value 


\begin{tabular}{ccl}
\hline No & Tipologi Nilai & \multicolumn{1}{c}{ Definisi } \\
\hline 1. Bequest value & $\begin{array}{l}\text { Nilai ekonomi yang diperoleh dari manfaat pelestarian } \\
\text { ekosistem/sumberdaya untuk kepentingan generasi masa depan }\end{array}$ \\
2. Existence value & $\begin{array}{l}\text { Nilai ekonomi yang diperoleh dari sebuah persepsi bahwa } \\
\text { keberadaan (existence) dari sebuah ekosistem/sumberdaya itu ada, } \\
\text { terlepas dari apakah ekosistem/sumberdaya tersebut dimanfaatkan } \\
\text { atau tidak }\end{array}$ \\
& &
\end{tabular}

a. Manfaat langsung (direct use value)

Manfaat langsung ekosistem dinilai menggunakan formula (Fauzi, 2002):

$\mathrm{TML}=\mathrm{ML1}+\mathrm{ML} 2+\mathrm{ML} 3 \ldots+$ MLn

Dimana :

TML $=$ Total Manfaat Langsung

ML1 = Manfaat Langsung Perikanan

ML2 = Manfaat Langsung Pariwisata

ML3 = Manfaat Langsung Penelitian

b. Manfaat tidak langsung (indirect use value)

Manfaat pilihan merupakan nilai yang diberikan oleh masyarakat atas adanya pilihan untuk menikmati sumberdaya alam pada masa datang dengan formula (Fauzi \& Anna, 2005):

$\mathrm{MP}=(\mathrm{Nb} \times \mathrm{L})$

Dimana :

MP = Manfaat Pilihan

$\mathrm{Nb}=$ Nilai Keanekaragaman Hayati

L = Luas Kawasan Terumbu Karang (ha)

Manfaat keberadaan dinilai dari manfaat yang dirasakan masyarakat karena keberadaan sumberdaya menggunakan formula (Fauzi, 2002):

$$
M E=\sum_{i=1}^{n}(M E i) / n
$$

Dimana:

$\mathrm{MEi}=$ Manfaat Ekosistem dari responden kei

$\mathrm{n}=$ Jumlah responden

Manfaat dihitung dengan metode Willingness to Pay (kesediaan membayar masyarakat).

Tabel 2 Pendekatan dan Teknik yang Digunakan Dalam Penilaian Setiap Tipologi

\begin{tabular}{|c|c|c|}
\hline No. & Pendekatan & Teknik \\
\hline 1 & $\begin{array}{l}\text { Direct use } \\
\text { value }\end{array}$ & $\begin{array}{l}\text { Change-in- } \\
\text { productivity } \\
\text { Approach or Effect of } \\
\text { Production (EOP) }\end{array}$ \\
\hline 2 & $\begin{array}{l}\text { Nilai } \\
\text { pengeluaran } \\
\text { langsung }\end{array}$ & $\begin{array}{l}\text { Cost Effectiveness } \\
\text { Analysis (CEA) }\end{array}$ \\
\hline 3 & $\begin{array}{l}\text { Nilai pasar } \\
\text { implisit } \\
\text { (surrogate } \\
\text { market) }\end{array}$ & $\begin{array}{l}\text { Hedonic } \\
\text { Value/Property-value } \\
\text { approach }(P V)\end{array}$ \\
\hline 4 & $\begin{array}{l}\text { Nilai } \\
\text { pengeluaran } \\
\text { implisit }\end{array}$ & $\begin{array}{l}\text { Replacement Cost } \\
\text { (Rep.C) }\end{array}$ \\
\hline 5 & $\begin{array}{l}\text { Artificial } \\
\text { market }\end{array}$ & $\begin{array}{l}\text { Contingent Valuation } \\
\text { Method }\end{array}$ \\
\hline 6 & Non-WTP & $\begin{array}{l}\text { Energy Theory of } \\
\text { Value - Energy } \\
\text { Analysis (EA) }\end{array}$ \\
\hline
\end{tabular}




\section{HASIL DAN PEMBAHASAN}

Kawasan TWP Gita Nada terdapat ekositem terumbu karang seluas 2.701,6 hektar dengan persentase tutupan karang hidup sangat rendah berkisar antara 15- $27 \%$ (DKP Lobar, 2013). Genus karang yang ditemukan adalah Acropora, Stylophora, Montipora, Astreopora, Herpolitha, Sandalolitha, Fungia, Leptoseris, Pavona, Pachyseries, Pseudosiderastrea, Turbinaria, Physogyra, Plerogyra, Cyphastrea, Diploastrea, Echinopora, Favia, Favites, Goniastrea, Montastrea, Oulophyllia, Platygyra, Ctenactis, Fungia, Heliofungia, Podabacia, Seriatopora, Psammacora, Hydnophora, Lobophyllia, Mussa, Symphyllia, Galaxea, Pectinia, Stylophora, Goniopora, dan Porites. Kondisi ini mencerminkan degradasi yang sangat serius. Mansyur \& Alam (2016) menyatakan bahwa kerusakan terumbu karang berdampak signifikan terhadap kehilangan nilai ekonomi dan ekologi ekosistem.

\section{Nilai Manfaat Langsung (DUV)}

Manfaat langsung terumbu karang di TWP Gita Nada meliputi: (1) pemanfaatan untuk perikanan tangkap; (2) pemanfaatan untuk pariwisata; dan (3) pemanfaatan untuk pendidikan dan penelitian (Barbier, 1993; Barton, 1994; Bockstael et al., 2000). Kuantifikasi nilai pemanfaatan perikanan tangkap di kawasan ekosistem terumbu karang menggunakan metode harga pasar dari hasil tangkapan ikan (market price), sedangkan kuantifikasi nilai pariwisata dan penelitian/pendidikan menggunakan metode pasar pengganti dengan menilai dari suatu perbaikan kualitas lingkungan (surrogate market price) (Barton, 1994).

Produksi perikanan tangkap Kabupaten Lombok Barat sebesar 757,78 ton per tahun pada tahun 2017. Sementara itu, produksi perikanan tangkap di Kecamatan Sekotong dan sekitarnya sebesar 376 ton. Jenis ikan hasil tangkap yang menjadi target adalah famili Lutjanidae (kakap), Lethrinidae, Scaridae (kaka tua), Labridae, Serranidae (kerapu) Acanthuridae dan Siganidae (DKP NTB, 2018). Nilai ekoistem terumbu karang sangat berpengaruh terhadap besarnya perolehan nilai kontribusi perikanan karena merupakan habitat penting bagi ketersediaan sumberdaya ikan (Nastiti et al., 2015).

Tabel 3 Analisis Nilai Manfaat Langsung Terumbu Karang di TWP Gita Nada

\begin{tabular}{ccrrr}
\hline No. & \multicolumn{1}{c}{ Penggunaan } & Benefits (IDR) & \multicolumn{1}{c}{ Cost (IDR) } & \multicolumn{1}{c}{ Net Value (IDR) } \\
\hline 1. & Perikanan tangkap & $9.068,371,849.90$ & $3.315,034,600.00$ & $5.753,337,249.90$ \\
2. & Pariwisata & $37,448,434,935.98$ & $11,753,121,750.00$ & $25,695,313,203.98$ \\
3. & Pendidikan dan rekreasi & & & $8,758,000,000.00$ \\
\hline \multicolumn{2}{l}{ Total } & $34,453,313,203.98$ \\
\hline
\end{tabular}


Nilai Manfaat Tidak Langsung (IUV)

Produktivitas primer sumber daya karang sebesar 1.800- 4.200 gram carbon per meter persegi pertahun (Bunt, 1975). Kuantifikasi nilai fungsi pelindung pantai menggunakan metode biaya pengganti untuk membangun perlindungan pantai (replacement cost). Biaya membangun penahan gelombang sebesar Rp 32,380,952.38 per meter (Permen PUPR No.07/PRT/M/2015). Nilai fungsi pelindung pantai dengan panjang pantai TWP Gita
Nada yang diperkirakan terpengaruh sepanjang 800 meter, sehingga manfaat tidak langsung terumbu karang sebagai penyerap karbon dan pelindung pantai di kawasan TWP Gita Nada seluas 2.701,6 hektar (Tabel 4). Nilai ekonomi bagi perlindungan pantai dari fungsi ekosistem terumbu karang memiliki nilai yang sangat signifikan dalam perlindungan pantai, yaitu sebesar 55\% dari tortal nilai ekonomi (O’Gara, 2012)

Tabel 4 Analisis nilai manfaat tidak langsung terumbu karang di TWP Gita Nada

\begin{tabular}{ccrrr}
\hline No. & Penggunaan & Panjang $(\mathbf{m}) /$ Luasan $\left(\mathbf{m}^{\mathbf{2}}\right)$ & Cost (IDR) & Net Value (IDR) \\
\hline 1. & Pelindung pantai & 800 & $32,380,952.38$ & $25,904,761,904.00$ \\
2. & Penyerap carbon & 8.104 .800 & 2,400 & $19,451,520,000.00$ \\
\hline \multicolumn{5}{c}{ Total } \\
\hline
\end{tabular}

\section{Nilai Pilihan (Option Value/OV)}

Nilai pilihan adalah nilai keanekaragaman hayati ekosistem terumbu karang. Dengan menggunakan metode transfer keuntungan (benefit transfer) yang mengacu pada nilai keanekaraman terumbu karang per $\mathrm{km}^{2}$ per tahun (Cesar et al., 2002) sebesar US \$ 100 per hektar. Dengan luas terumbu karang yang dimiliki TWP Gita Nada mencapai 2.701,6 ha, maka nilai keanekaragaman hayati terumbu karang di TWP Gita Nada seperti yang ditunjukan pada Tabel 5.

Tabel 5 Analisis Nilai Pilihan Terumbu Karang di TWP Gita Nada

\begin{tabular}{lrrrr}
\hline No. & Penggunaan & Luasan (ha) & Cost (IDR) & Net Value (IDR) \\
\hline 1. & Keanekaragaman Hayati & $2.701,6$ & $1,450,000$ & $3,917,320,000.00$ \\
\cline { 2 - 4 } & & Total & & $3,917,320,000.00$
\end{tabular}

\section{Nilai Pewarisan (Bequest Value/BV)}

Nilai pewarisan adalah nilai kompensasi untuk menjaga atau melestarikan terumbu karang melalui program dan kegiatan perlindungan dan pengawetan.
Kualifikasi nilai menggunakan metode biaya kompensasi yang dikeluarkan untuk melaksanakan kegiatan pelestarian dan perlindungan (Compensation cost). Untuk merehabilitasi terumbu karang rata-rata dibutuhkan biaya sebesar US\$40.000/hektar 
(Edwards \& Gomez, 2007). Selama lima tahun terakhir biaya yang dibutuhkan untuk rehabilitasi terumbu karang TWP Gita Nada ditunjukan pada Tabel 6. Kesehatan terumbu karang sangat berpengaruh terhadap kesejahteraan komunitas lokal karena akan meampu menghasilkan nilai milliaran rupiah, karena itu pengelolaan terumbu karang harus dilakukan secara berkelanjutan untuk warisan generasi yang akan datang (Asadi, 2017).

Tabel 6 Analisis nilai pewarisan terumbu karang di TWP Gita Nada

\begin{tabular}{lrrrr}
\hline No & \multicolumn{1}{c}{ Penggunaan } & Luasan (ha) & Cost (IDR) & Net Value (IDR) \\
\hline 1. & $\begin{array}{l}\text { Rehabilitasi Ekosistem } \\
\text { Terumbu Karang }\end{array}$ & 5 & $580,000,000$ & $2,900,000,000$ \\
\hline \multicolumn{5}{c}{ Total } \\
\hline
\end{tabular}

\section{Nilai Eksistensi (EV)}

Nilai eksistensi adalah nilai persepsi akan keberadaan (existence) terumbu karang di TWP Gita Nada, terlepas dari apakah terumbu karang tersebut dimanfaatkan atau tidak. Hasil wawancara, diperoleh nilai total kesediaaan menerima (WTP) berdasarkan nilai median sebesar Rp.25.000.000. Nilai preferensi masyarakat dipengaruhi oleh factor kurangnya pengetahuan masyarakat trehadap arti penting fungsi ekologis terumbu karang. Berdasarkan data BPS Lombok Barat (2018), jumlah penduduk Desa Sekotong Barat yang berbatasan langsung dengan TWP Gita Nada adalah sekitar 2.454 jiwa, sehingga estimasi nilai eksistensi (EV) terumbu karang seperti yang ditunjukan pada Tabel 7.

Tabel 7 Analisis Nilai Pewarisan Terumbu Karang di TWP Gita Nada

\begin{tabular}{lcrrc}
\hline No. & Penggunaan & Jumlah Penduduk (jiwa) & Cost (IDR) & Net Value (IDR) \\
\hline $\begin{array}{l}\text { 1. } \\
\text { WTP dan preferensi } \\
\text { komunitas }\end{array}$ & 2.454 & $25,000,000$ & $61,350,000,000.00$ \\
\hline & Total & $61,350,000,000.00$ \\
\hline
\end{tabular}

Nilai manfaat keberadaan ekosistem terumbu karang diperoleh dengan menggunakan CVM (contingent valuation method) yang merupakan representasi seberapa besar setiap individu yang ditunjuk sebagai responden memberikan nilai untuk keinginan membayar bagi keberadaan sumberdaya terumbu karang. Putri (2009) melaporkan bahwa rendahnya nilai ekosistem terumbu karang dibandingkan nilai sesungguhnya merupakan faktor yang mempengaruhi terjadinya kerusakan ekosistem terumbu karang di Kepulauan Seribu. Hasil wawancara dengan responden 
yang telah dikelompokkan secara berjenjang sesuai tingkat pendidikan menunjukkan bahwa besarnya kemauan membayar bagi keberadaan sumberdaya terumbu karang sangat dipengaruhi oleh tingkat pendidikan dan pemahaman masyarakat terhadap pentingnya ekosistem terumbu karang serta jumlah pendapatan (Mira et al., 2017). Penelitian lainnya menunjukkan bahwa $46 \%$ responden bersedia membayar pelestarian terumbu karang, dengan motif warisan dan kepedulian terhadap generasi mendatang dengan WTP rata-rata Rp 128,539.18 (Subade \& Fransisco, 2014).

Berdasarkan analisis total nilai ekonomi terumbu karang di TWP Gita Nada adalah sebesar Rp. 147,976,915,107.98

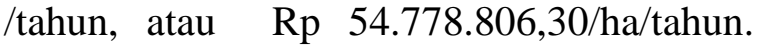
Secara rinci nilai fungsi dan manfaat terumbu karang kawasan di TWP Gita Nada ditunjukan pada Tabel 8 .

Tabel 8 Total Nilai Manfaat Terumbu Karang di TWP Gita Nada

\begin{tabular}{|c|c|c|c|}
\hline $\begin{array}{c}\text { Sumber Daya } \\
\text { Terumbu Karang }\end{array}$ & Fungsi dan Manfaat & Metode & $\begin{array}{l}\text { Nilai Manfaat Bersih } \\
\text { (Rp/tahun) }\end{array}$ \\
\hline \multirow[t]{3}{*}{ Direct Use Value } & Perikanan Tangkap & Market price & $5.753,337,249.90$ \\
\hline & Pariwisata & $\begin{array}{l}\text { Surrogate market } \\
\text { price }\end{array}$ & $25,695,313,203.98$ \\
\hline & $\begin{array}{l}\text { Penelitian dan } \\
\text { Pendidikan }\end{array}$ & $\begin{array}{l}\text { Surrogate market } \\
\text { price }\end{array}$ & $8,758,000,000.00$ \\
\hline \multirow[t]{2}{*}{ Indirect Use Value } & Perlindungan Pantai & Replacement cost & $25,904,761,904.00$ \\
\hline & $\begin{array}{l}\text { Pengurangan Emisi } \\
\text { dengan menyerap } \\
\text { Carbon dan } \\
\text { melepaskan Oksigen }\end{array}$ & $\begin{array}{l}\text { Damage avoided } \\
\text { cost }\end{array}$ & $19,451,520,000.00$ \\
\hline Option Value & $\begin{array}{l}\text { Keanekaragaman } \\
\text { Hayati }\end{array}$ & Benefit transfer & $3,917,320,000.00$ \\
\hline Bequest Value & WCS_Ristek & Compensation costs & $2,900,000,000.00$ \\
\hline Existence Value & $\begin{array}{l}\text { Persepsi bahwa } \\
\text { keberadaannya } \\
\text { terhadap ekosistem } \\
\text { lainnya serta sosial } \\
\text { budaya masyarakat }\end{array}$ & WTP - CVM & $61,350,000,000.00$ \\
\hline
\end{tabular}

Total Economic Value $\quad 147,976,915,107.98$

\section{KESIMPULAN}

1. Pentingnya zonasi ekosistem terumbu karang yang jelas, meliputi daerah preservasi (inti), penyangga dan daerah eksploitasi. Kualifikasi dan batas setiap zona perlu ditetapkan secara definitif demi kemudahan pencantumannya dalam peraturan.

2. Investasi pengembangan TWP Gita Nada didasarkan pada pendekatan complete assesment dan net incremental benefit yang positif dari strategi pengembangan yang direncanakan 
3. Instrumen hukum dan perundangundangan yang rinci, didalamnya harus mengatur hak dan tanggung jawab investor, jaminan terhadap kelestarian sumber daya terumbu karang, besaran denda serta mekanisme pembayaran dan sanksi bagi pelanggar.

4. Pentingnya institusi pengawas yang independen dengan penegakan aturan yang tegas bagi pelanggar atau perusak ekosistem terumbu karang.

5. Meningkatkan kesadaran dan partisipasi masyarakat lokal perlu ditumbuhkan melalui berbagai macam pendekatan.

Penetapan sanksi bagi perusak terumbu karang dapat ditetapkan bersadarkan nilai total ekonomi terumbu karang.

\section{DAFTAR PUSTAKA}

[BPS Lombok Barat] Badan Pusat Statistik Kabupaten Lombok Barat. 2018. Kecamatan Sekotong Dalam Angka. BPS Kabupaten Lombok Barat, Gerung.

[DKP Lombok Barat] Dinas Kelautan dan Perikanan Kabupaten Lombok Barat. 2013. Laporan Identifikasi Potensi Sumberdaya di Kawasan Gili tangkong, Nanggu dan Sudak. DKP Lombok Barat, Gerung. 117 hal.

[DKP NTB] Dinas Kelautan dan Perikanan Provinsi NTB. 2018. Statistik Perikanan Tangkap Provinsi Nusa Tenggara Barat. DKP NTB, Mataram.

[KKP] Kementerian Kelautan dan Perikanan. 2007. Undang-Undang Nomor 27 Tahun 2007 tentang Pengelolaan Wilayah Pesisir dan Pulau-Pulau Kecil. KKP, Jakarta.

[KPUPR] Kementerian Pekerjaan Umum dan Perumahan Rakyat. Permen PUPR No.07/PRT/M/2015 tentang
Standarisasi Biaya Rekonstruksi Pembangunan Fisik. KPUPR, Jakarta.

Asadi M A, Andrimida A. 2017. Economic Valuation of Coral Reffs Ecosystem of Bangsring Banyuwangi Indonesia. ECSOFIM 4(2): 144-152.

Barbier E B. 1993. Sustainable use of wetlands valuing tropical wetland benefits: Economic methodologies and applications. The Geographical Journal 159(1): 22-32.

Barton D N. 1994. Economic Factors and Valuation of Tropical Coastal Resources. SMR-Report 14/94, Bergen, Norway. 128 pp.

Bockstael N E, Freeman A M, Kopp R J, Portney P R, Smith V K. 2000. On measuring economic values for nature. Environ Sci Technol 34(8): 1384-1389.

Bunt J. 1975. Primary Productivity of Marine Ecosystems. In: Lieth H \& Whittaker R $\mathrm{H}$ [eds]. Primary Productivity of the Biosphere. Springer-Verlag, New York.

Cesar H, Beukering P V, Pintz S, Dierking J. 2002. Economic valuation of the coral reefs of Hawaii. Cesar Environmental Economics Consulting, Netherland.

Edwards A J, Gomez E D. 2007. Reef Restoration Concepts and Guidelines: making sensible management choices in the face of uncertainty. Capacity Building for Management Programme/Coral Reef Targeted Research: St. Lucia. 38 pp.

Fauzi A, Anna S. 2005. Studi Valuasi Ekonomi Perencanaan Kawasan Konservasi Selat Lembeh, Sulawesi Utara. USAID, DKP, dan Mitra Pesisir, Jakarta

Fauzi A. 2002. Ekonomi Sumberdaya Alam dan Lingkungan: Teori dan 
Aplikasinya. PT. Gramedia Pustaka Utama, Jakarta.

Mansyur A. Alam L S. 2016. Valuasi ekosistem terumbu karang Wakatobi. Jurnal Bisnis Perikanan FPIK UHO, 3(1): 1-12.

McCook, L. J., Almany, G. R., Berumen, M. L., Day, J. C., Green, A. L., Jones, G. P., Leis, J. M., Planes, S., Russ, G. R., Sale, P. F., \& Thorrold, S. R. (2009). Management under uncertainty: Guidelines for incorporating connectivity into the protection of coral reefs. Coral Reefs, 28(2), 353-366. https://doi.org/10.1007/s00338-0080463-7

Mira, Saptanto S, Hikmah. 2017. Valuasi nilai ekonomi terumbu karang di Banda Neira. J Sosek KP 12(1): 11-20.

Nastiti M W, Saputra S, Wijayanto D, 2015. Valuasi ekonomi ekosistem terumbu karang di Perairan Karang Kelop Kendal. Diponegoro Journal of Maquares 4(3): 188-194.

O'Gara T. 2012. Economic valuation of a traditional fishing ground on the coral coast in Fiji. Ocean \& Coastal Management 56: 44-55.
Putri I A P. 2009. Valuasi Ekonomi Terumbu Karang Kawasan Konservasi Laut Kepulauan Seribu. Tesis [tidak dipublikasi]. Sekolah Pascasarjana IPB, Bogor.

Subade R F, Fransisco H A. 2014. Do nonusers value coral reefs? : Economic valuation of conserving Tubbataha Reefs, Philippines. Ecological Economic 102: 24-32.

Witomo, C. M., Harahap, N., \& Kurniawan, A. (2020). Nilai Manfaat Pariwisata Ekosistem Terumbu Karang Taman Wisata Perairan Gita Nada Sekotong Lombok. Jurnal Sosial Ekonomi Kelautan Dan Perikanan, 15(2), 169. https://doi.org/10.15578/jsekp.v15i2.92 34

Yulianto, E. Y. F., Mawardi, W., \& Purwangka, F. (2019). Penentuan Lokasi Penangkapan Ikan Karang Di Kawasan Konservasi Perairan Gita Nada, Lombok Barat. Jurnal IPTEKS Pemanfaatan Sumberdaya Perikanan, 5(10), 106-131. https://doi.org/10.20956/jipsp.v5i10. 6204 